\title{
Sustainable energy from dairy farm waste using a Microbial Fuel Cell (MFC)
}

\author{
XiaoNan Zhang, Laura Porcu, John M. Andresen* \\ Department of Chemical and Environmental Engineering, University Park, Nottingham, NG7 2RD \\ * Corresponding author. Tel: +44 115951 4640, Fax: +44 115951 4115, \\ E-mail: enzjma@exmail.nottingham.ac.uk
}

\begin{abstract}
A dairy farm waste which include milk waste, unconverted feed and bedding, cow manure and cow slurry water have been applied as raw materials to produce renewable energy using a continuous flow membrane-less microbial fuel cell (MFC). The COD content decreased with 98\% from 33,600 J/L to $558 \mathrm{~J} / \mathrm{L}$ within 6 days by turning the organic content into electricity and hydrogen. The voltage generated reached a peak of $1.6136 \mathrm{mV}$, which indicating that dairy farm waste can be an appropriate resource for MFC. The total energy of hydrogen gas was 38,338J/L on the sixth day, which suggesting that about $80 \%$ of the energy stored in the COD was transferred into hydrogen gas. The nitrogen content of the farm waste slurry also decreased $20 \%$ during the first 24 hours indicating that MFC can be used for nitrogen harvesting.
\end{abstract}

Keywords: 1. Biomass fuel; 2. Renewable energy; 3. Dairy farm; 4. MFC; 5. hydrogen production

\section{Introduction}

There are close to 2 million dairy cows in the UK producing an estimate of 70 million $\mathrm{m}^{3}$ of slurry annually. Since each $\mathrm{m}^{3}$ of slurry contains $200-250 \mathrm{kwh}$, it can be considered as one of the largest sustainable energy resource in the UK. Due to increasing use of intensive farming methods, agriculture derived wastes will continue to increase, especially within the livestock farming. From 1961 to 1999, there was a 34\% increase of the total livestock numbers in UK (BERR \& DEFRA, 2003). Farm wastes, such as slurry, dirty water, silage liquor and manure, need to be treated and disposed in an environmentally appropriate way. For dairy farms, most of the slurry wastes are used as fertilizer to grow winter feed crops for the animals. However, there are future logistical and economic constraints, such as for nitrate vulnerable zones were spreading is limited to $170 \mathrm{~kg} / \mathrm{ha}$ (Cinar et al., 2004). The restriction is to stop nutrients run-off into surrounding ground water from manure spread on the fields. Removal of nitrate is an option, but it is not easy to completely remove ammonia and other nitrogen compounds from wastewater or slurry water by conventional wastewater treatment technologies (Jetten et al., 2002). There are significant hazardous environmental impacts of nitrogen. For example, due to bacteria oxidation into nitrate, depletion of dissolved oxygen in receiving streams and promotion of eutrophication that are toxic to most aquatic organisms. Moreover, high concentration of nitrate in groundwater is also harmful to human health, because some diseases could occur, such as gastric cancers and infant methaemoglobinemia (Jetten et al., 2002). Therefore, there is a great potential for nitrate rich dairy farm waste to be used as feedstock in microbial fuel cells. In these processes, the available nutrients can be converted into energy resulting in reduced environmental impact and lowered energy cost for conventional dairy farms could be offset (Young and Pian, 2003).

\section{Methodology}

The Microbial Fuel Cell is a technology that can be used to generate electricity from waste water or animal slurry water by employing microorganisms to digest inorganic and organic compounds (Liu and Logan, 2004). The catalytic reaction of bacteria produces electrons which are transferred to the anode, i.e. the negative terminal, directly or by electron mediators (Liu and Logan, 2004). The microbes also produce protons that travel from the anode 
chamber to the cathode chamber. The electrons from the anode travel through an external load and recombine with the protons at the cathode to form electric current and hydrogen.

In this study, a continuous flow membrane-less $1 \mathrm{~m}^{3}$ MFC was used at $25^{\circ} \mathrm{C}$ temperature with a flow rate of $0.8 \mathrm{~L} / \mathrm{min}$. The MFC pilot plant was located at the Sutton Bonington campus of the University of Nottingham (Figure 1). The microbial culture available in the liquid cow manure from a 3 million L storage tank at the Sutton Bonington Campus was used as inoculums.. A HACH spectrophotometer DR2500 (Inc.US) was used to conduct COD tests. An HPR-20 MS was used to quantify the hydrogen produced. The total nitrogen removal was been determined by the Kjeldahl method..

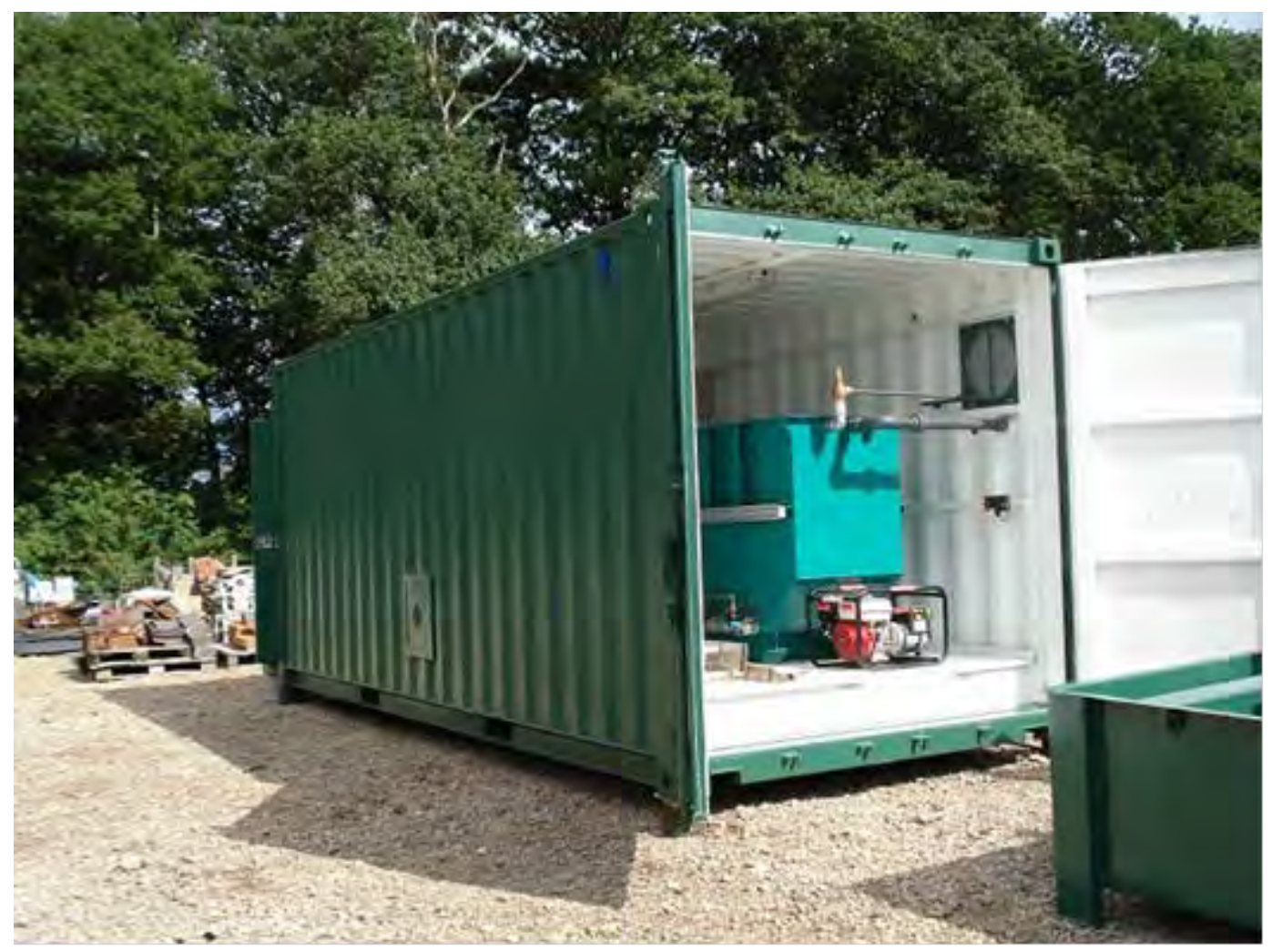

Figure 1MFC pilot plant of the University of Nottingham

\section{Results}

The COD value decreased rapidly during the first 2 days and then slightly decreased until the sixth day, as shown in Figure 2. The initial COD energy level was 33,600 J/L, and finally reached $558 \mathrm{~J} / \mathrm{L}$ after 6 days. The overall removal of initial COD energy was 98\%. This indicates that the microbial fuel cell is very active during the initial stage where nutrients, such as nitrates, are abundant. 


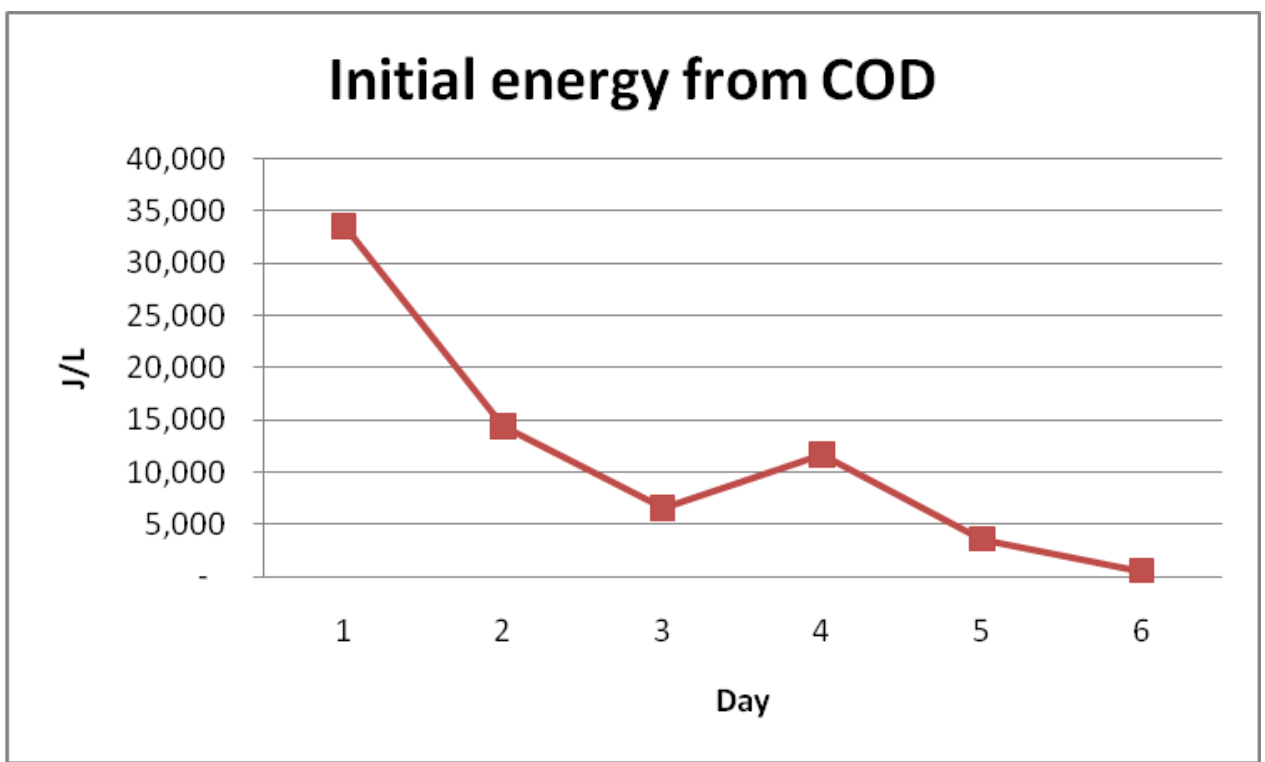

Figure 2 COD removal for MFC

Figure 3 shows the voltage variation between day $1(0)$ to day $6(5)$. The initial voltage increased from $1.2 \mathrm{mV}$ to $1.6 \mathrm{~mW}$ within two days. Correspondingly, the largest amount of COD was removed from the first day to the third day. Therefore, the voltage achieved the highest value $(1.6 \mathrm{mV})$ on the third day and stayed stable until the end of forth day. As the COD energy is depleted, the voltage decreases on the sixth day.

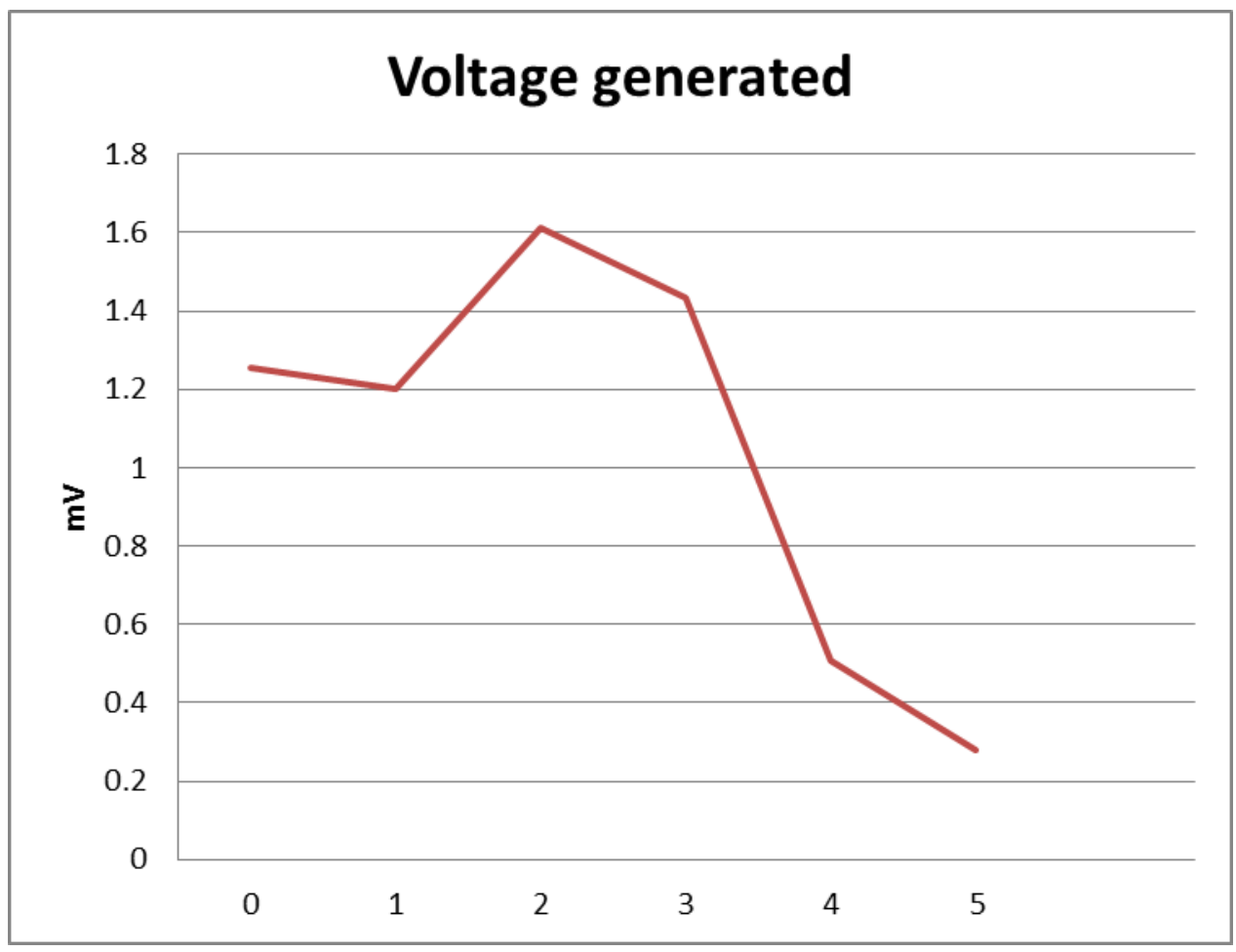

Figure 3 Electricity generated from MFC

Figure 4 shows the hydrogen production variation between day 1 (0) to day 6 (5). There was a rapid increase in the hydrogen produced within the first two days corresponding with the rapid fall in COD and increase in voltage generated. The energy content of hydrogen was 
increasing continuously and finally achieved 38,333 $\mathrm{J} / \mathrm{L}$, which indicated that $80 \%$ of the COD energy was transferred to hydrogen gas.

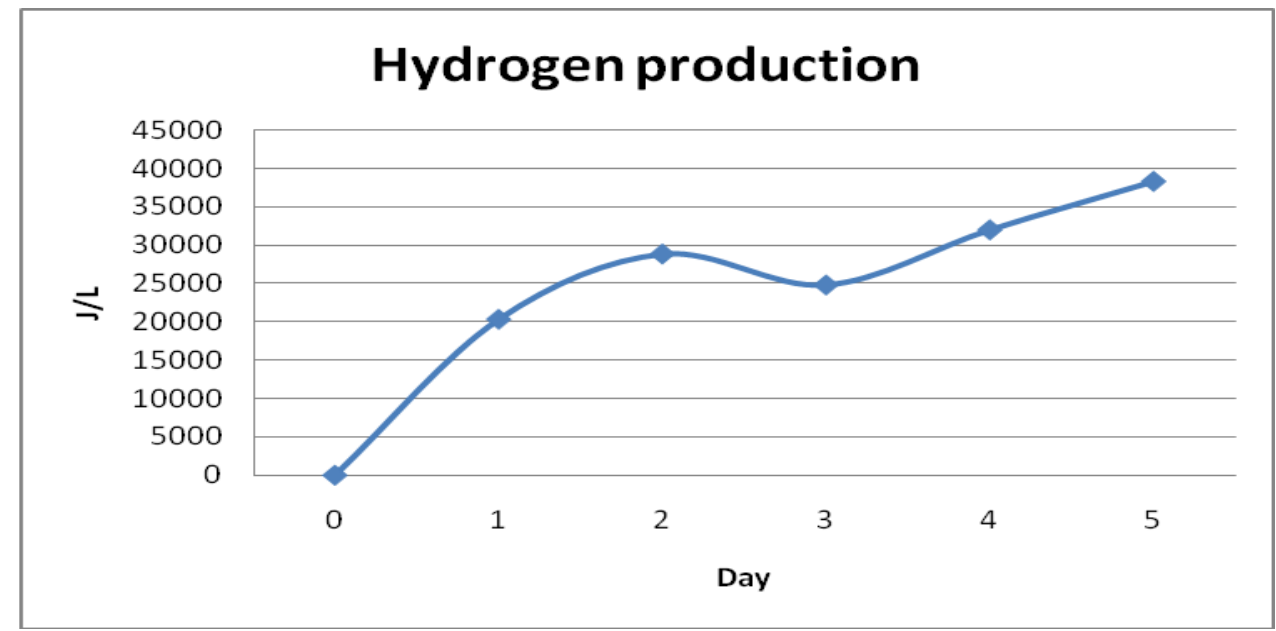

Figure 4 Energy to hydrogen production

According to the analysis, the content of nitrogen was decreasing continuously. There were $20 \%$ total nitrogen removals during the first 24 hours. That means organic nitrogen have been removed from liquid manure effectively by MFC, and stored in the MFC micro-organisms. The depletion of nitrate may also result in decreased microbial activity after day 4 .

\section{Conclusions}

The overall COD removal from dairy farm waste using a microbial fuel cell was $98 \%$ after 6 days. The highest value of voltage generated was $1.6136 \mathrm{mV}$ indicating that dairy farm slurry waste is an appropriate resource for MFC. It could supply certain amount energy for the dairy farm, and also, the carbon emission and the disposal charging could be reduced. There is also bio-hydrogen produced by MFC where $80 \%$ of the COD energy has been transferred to hydrogen gas. Moreover, there were 20\% nitrogen removals in the MFC during the first 24 hours. The most of nitrogen content of liquid slurry were immobilized in microbes indicating that available nitrate is a key for strong MFC activities.

\section{References}

[1] BERR\& DEFRA, Energy White Paper. Our Energy Future-Creating a Low Carbon Economy, TSO, 2003.

[2] S. Cinar, T.T. Onay, A. Erdincler, Co-disposal alternatives of various municipal wastewater treatment-plant sludges with refuse. Advances in Environmental Research 8, 2004, pp. 477-482.

[3] M. Jetten, M. Schmid, I. Schmidt, M. Wubben, U. van Dongen, W. Abma, et al., Improved nitrogen removal by application of new nitrogen cycle bacteria, Rev Environ Sci Bio Technol 1, 2002, pp. 51-63.

[4] L. Young, C.C.P. Pian, High-temperature, air-blown gasification of dairy-farm wastes for energy production, Energy 28, 2003, pp. 655-672.

[5] H. Liu, and B. E. Logan, Electricity generation using an air-cathode single chamber microbial fuel cell in the presence and absence of a proton exchange membrane, Environ. Sci. Technol., 38(14), 2004, pp.4040-4046. 